\title{
tiempo de mezcla en las hormigoneras
}

\author{
temps de malaxage des bétonnières
}

(«Supplément aux Annales de l'Institut Technique du Bâtiment et des Travaux Publics", núm. 139-140, jullo-agosto 1959. N. T. 42.)

Ei tiempo de mezcla en las hormigoneras de producción discontinua o por tongadas tiene importancia por influir notoriamente en la homogeneidad del hormigón; no debe ser ni muy largo ni muy corto.

Si es muy largo se corre el riesgo de obtener heterogeneidad por segregación, sobre todo en las hormigoneras de eje inclinado. Se aumenta el desgaste del ma- terial y conduce a un cambio de granulometría por molienda de los agregados cuando son friables o cuando existen elementos muy gruesos en el hormigón.

Si es muy corto da lugar a mezclas imperfectas, mala distribución de agregados y cemento y una heterogeneidad considerable del hormigón.

El tiempo de mezcla es función de:

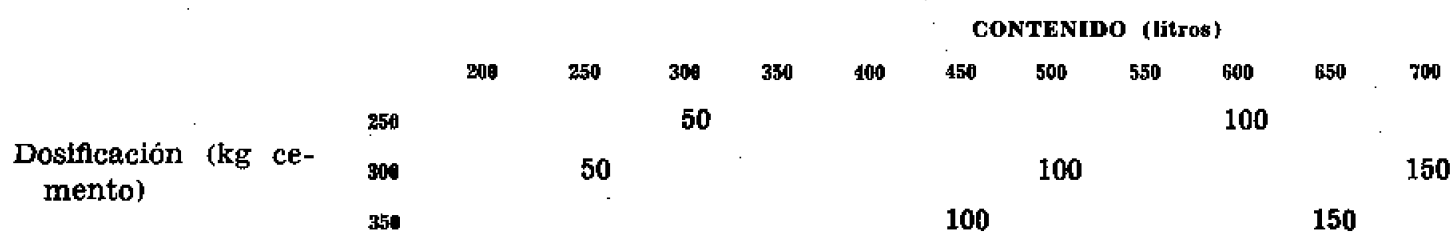

- la naturaleza y dimensión de los agregados;

- la velocidad de rotación de los tambores;

- la plasticidad de la mezcla estudiada;

- la cantidad de agua contenida en el hormigón;

- la cantidad de cemento;

- el volumen de la cuba y la carga de hormigón.

Por razones de comodidad y para facilitar la precisión, es bueno prever las composiciones en función del número de sacos de cemento. Para una composición tipo de $800 l$ de grava, $400 l$ de arena y 250,300 y $350 \mathrm{~kg}$ de cemento, puede establecerse una tabla de donde resulta que, para ciertas hormigoneras, es posible hacer dosificaciones con sacos enteros.

\section{¿QUE VENTAJAS TIENE EL OBTENER UN HORMIGON HOMOGENEO?}

- Una utilización perfecta del aglomerante, el cual se encuentra convenientemente humedecido y repartido en el interior de la masa.

- La humectación correcta de los granulados para obtener el grado de plasticidad deseado. 
- Una buena distribución de aditivos, si los hay.

- Una dispersión pequeña alrededor de la resistencia media $y$, en consecuencia, un riesgo menor de tener algunos resultados inferiores al mínimo impuesto por

El tiempo de mezcla en la hormigonera es suficiente si los áridos gruesos están brillantes $\mathrm{y}$ perfectamente recubiertos.

En las mejores condiciones, el tiempo de mezcla puede ser de sesenta segundos. En condiciones difíciles, es necesario, a veces, llegar hasta tres minutos.

Veamos a continuación algunos tiempos de mezcla teóricos suministrados por los fabricantes de hormigoneras en su publicidad: el Pliego de Condiciones.

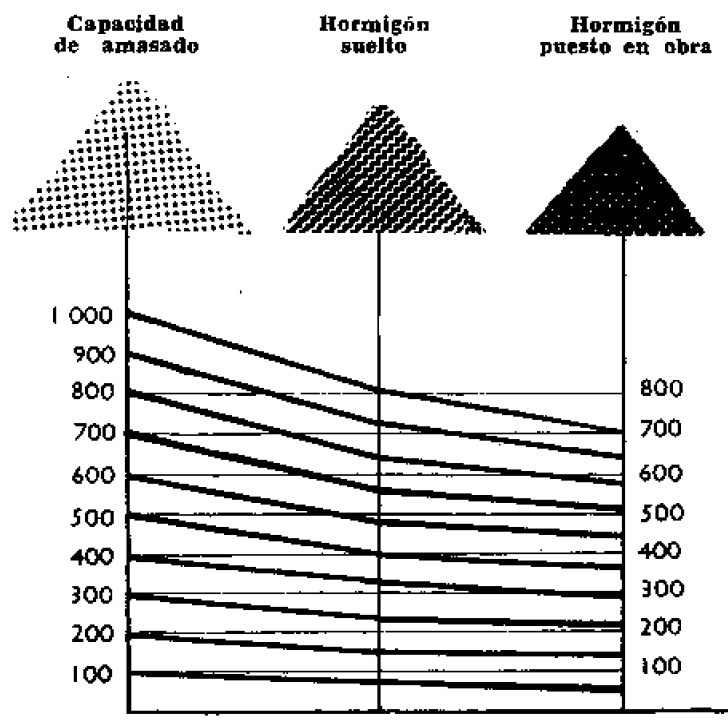

Fig. 2.

$\begin{array}{lc}\text { Rev/min } & \text { Tiempo } \\ & \\ 17 & 20 / 30 \mathrm{~s} \\ 16 & 1 \mathrm{mn} \\ 21 & 1 \mathrm{mn} \\ 15,3 & 1 \mathrm{mn} \\ 13 & 1 \mathrm{mn} \mathrm{30} \mathrm{s}\end{array}$

1." La capacidad de mezcla (volumen aparente total de materiales que puede contener la hormigonera antes de la mezcla).

2." El hormigón suelto (volumen del hormigón al final de la mezcla).

3." El volumen del hormigón puesto en obra (caso de una vibración media).

(Véase la figura 2.)

- El hormigón suelto representa aproximadamente el $80 \%$ de la capacidad de amasado.

El producto $\mathbf{D} \times \mathbf{N} \times$ i- $\mathbf{N}$ debe dar los resultados siguientes:

entre 350 y 400 para las hormigoneras de eje horizontal,

entre 350 y 450 para las horm goneras de eje inclinado.

Es preciso no perder de vista la relación que existe entre:
_- El hormigón puesto en obra representa el $70 \%$ de esta capacidad.

Los materiales puestos en hormigonera conducen, pues, a un volumen puesto en obra con una reducción del $30 \%$, aproximadamente.

F. S. S. 